\title{
Salmonella Septic Arthritis Complicating Rheumatoid Arthritis in a Patient with Total Knee Replacement
}

\author{
Fareeda Boland ${ }^{a}$ Prashant Kaushik ${ }^{b}$ Edet E. Udo ${ }^{a, c}$ \\ Vincent O. Rotimi ${ }^{a, c}$ Anand N. Malaviya ${ }^{b, c}$ \\ Departments of aMicrobiology, and ${ }^{b}$ Medicine, Mubarak Al-Kabeer Hospital, and \\ cFaculty of Medicine, Kuwait University, Kuwait
}

\section{Key Words}

Septic arthritis - Rheumatoid arthritis •

Salmonella Prosthetic knee

\begin{abstract}
Objective and Importance: Salmonella septic arthritis (SSA) in any age group is a relatively rare disease. The prime objective of this communication is to report a relatively uncommon presentation of SSA in a prosthetic knee joint of a patient with rheumatoid arthritis. Clinical Presentation: We report a 51-yearold lady with rheumatoid arthritis and total knee replacement who, while on methotrexate and azathioprine, developed Salmonella enteritidis bacteraemia complicated by septic monoarthritis of the left prosthetic knee. The same organism, using pulsed-field gel electrophoresis typing method, was isolated
\end{abstract}

from the blood, joint aspirate and stool. Intervention: She was aggressively treated with antibiotics by giving the maximum dose of ceftriaxone, $2 \mathrm{~g}$ intravenously every $8 \mathrm{~h}$ for 4 weeks. In addition, close drainage with syringe and needle was also done on a few occasions. She responded well to this regimen. Follow-up for approximately 1 year at the clinic has been uneventful. Conclusion: SSA in a patient with a history of diarrhoea and a recent visit to the Indian subcontinent should be investigated for salmonella infection. Adequate antibiotic therapy, with repeated close drainage of the joint, is recommended for SSA in a prosthetic joint.

Prof. Vincent O. Rotimi

Department of Microbiology

Faculty of Medicine, Kuwait University

PO Box 24923, Safat 13110 (Kuwait)

Tel. +965 5312300 ext.6509, E-Mail Vincent@hsc.kuniv.edu.kw 


\section{Introduction}

The commonest manifestation of salmonellosis is gastro-enteritis, which accounts for about $70 \%$ of the cases. Extra-intestinal tractlocalized infections are not as common and usually follow salmonella bacteraemia. Bone and joint involvement are unusual [1,2]. Salmonella septic arthritis (SSA) in any age group is a relatively rare complication of salmonella infection in the developed countries, reactive arthritis being the most frequent manifestation [3, 4]. A few cases of SSA have been reported in HIV-infected patients, patients with sickle cell disease and just one in a renal transplant recipient who had a total hip replacement [1-7]. So far only 13 cases of SSA have been reported that involve the knee [7], but none has been reported in a prosthetic total knee replacement. In this communication, we present a case of an infected prosthetic knee in a patient with severe underlying diseases complicated by bacteraemia due to $\mathrm{Sal}$ monella enteritidis group D.

\section{Case Report}

A 51-year-old female Indian patient, on methotrexate and azathioprine for rheumatoid arthritis, presented at the medical out-patient (Rheumatology) clinic with a 2-day history of fever, chills and swollen and painful right knee joint. She was a known insulindependent diabetic patient and had had a total knee replacement done abroad about 2 years earlier. The only significant past medical history was short bouts of diarrhoea a week preceding the onset of her symptoms when she visited India on a brief holiday. She is not a known sickler. On examination, she looked toxic, febrile (oral temperature $39^{\circ} \mathrm{C}$ ), her right knee was swollen and tender. She was hypertensive with a blood pressure of $160 / 90 \mathrm{~mm} \mathrm{Hg}$. A radiograph of the knee did not reveal any bony involvement. Arthrocentesis of the affected knee yielded $20 \mathrm{ml}$ of purulent synovial fluid (SF) with a WBC count of $>100,000 / \mathrm{mm}^{3}$, with $85 \%$ neutrophils. A sample was sent for culture and sensitivity. Blood samples were also taken for blood culture, haematological and biochemical profiles. A few days later, her stool specimens were sent for culture as well. Her CBC was as follows: WBC $8.2 \times$ $10^{9} / \mathrm{l} ; \mathrm{Hb} 10.5 \mathrm{~g} / \mathrm{dl}$; haematocrit $32.7 \%$ and platelet $284 \times 10^{9} / 1$. Her diabetes was well controlled with blood sugar of $5.2 \mathrm{mmol} / \mathrm{l}$, and other routine biochemical tests were normal except for slightly raised alkaline phosphatase; renal function was also normal. She was promptly commenced on intravenous ceftriaxone, $2 \mathrm{~g}$ every $8 \mathrm{~h}$ and intravenous metronidazole, $500 \mathrm{mg}$ every $8 \mathrm{~h}$. There was defervescence within $48 \mathrm{~h}$ but the medication continued for another 4 weeks. The metronidazole therapy was discontinued shortly after communicating the result of the blood culture to the ward. After satisfactory recovery in the ward, she was discharged 5 weeks after admission. A follow-up of approximately 1 year at Rheumatology Clinic was uneventful, and she has since regained baseline range of movement in that joint.

\section{Microbiological Investigations and Results}

In the Microbiology Laboratory, smears of the pus were made for gram stain and Ziehl-Neelsen (ZN) stain. The gram stain revealed numerous pus cells with scanty gram-negative bacilli. No acid fast bacilli were seen in the ZN stain. The pus material was plated onto a set of selective and non-selective media and incubated at the various appropriate atmospheric conditions, including anaerobic condition. The blood culture bottles were incubated inside the Bactec 9240 Blood Culture machine (Bio-Mérieux Inc., France). Within $18 \mathrm{~h}$ of incubation, both blood culture and pus culture yielded gram-negative bacilli which were later identified as $S$. enteritidis group D by the Vitek Aerobic Identification System (Bio-Mérieux Vitek Inc., Hazelwood, USA) and manual serogrouping with commercial antisera (Wellcome Diagnostics, Dartford, UK). The stool specimen also grew $S$. enteritidis with the same serogroup and sensitivity profiles as the other two isolates.

Susceptibility testing was initially done in the Vitek machine, and the results obtained tallied with those obtained by determining the minimum inhibitory concentrations (MICs) using the E test strips (AB Biodisk, Sweden). All the three isolates were susceptible to ampicillin, amikacin, ciprofloxacin, cefotaxime, ceftriaxone, piperacillin, piperacillin-tazobactam, cefuroxime and chloramphenicol, but resistant to cotrimoxazole.

Apart from being susceptible to the same antibiotics, DNA extracts of the blood and joint isolates were subjected to pulse-field gel electrophoresis (PFGE) to determine their relatedness. Briefly, the organisms 
were grown overnight in tryptic soy broth and then used to prepare agarose blocks as described previously [8], with the following modification: the lysis solution contained lysozyme $(1 \mathrm{mg} / \mathrm{ml})$ instead of lysostaphin. Blocks were digested with $X b a$ I (Gibco BRL) according to the manufacturer's instruction. Electrophoresis was performed with $1 \%$ agarose gel in $0.5 \mathrm{X}$ TBE buffer using a CHEF DR III apparatus (Bio-Rad Laboratories). The gel was run at $14^{\circ} \mathrm{C}, 6 \mathrm{~V} / \mathrm{cm}$ and $120^{\circ} \mathrm{C}$ switch angle for $22 \mathrm{~h}$. Linear ramp of switch times was $0.5-40 \mathrm{~s}$. The gels were stained in $0.5 \mathrm{mg} / \mathrm{l}$ ethidium bromide and photographed under UV illumination. The chromosomal patterns were examined and compared by the naked eye and then assigned to PFGE types. As can be seen, the strains shown in lanes 2 and 3 in figure 1, have identical DNA bands, proving that they are identical strains; lane 1 contained the control DNA bands.

\section{Discussion}

This communication presents an unusual case of $S$. enteritidis group D septic arthritis of a prosthetic knee in a patient with total knee replacement and underlying diseases such as rheumatoid arthritis and diabetes. Septic arthritis is a disease of children $[3,5,6]$ with Staphylococcus aureus and Haemophilus influenzae being the commonest pathogens [911]. Even though Salmonella infection is common in the developing countries, complications with septic arthritis and osteomyelitis are uncommon. However, in the SSA cases that have been published, $S$. cholerasuis and S. typhimurium are the commonest $[4,6,12$, 13]. A summary of a world literature review on SSA from 1983-1997 is shown in table 1.

The rarity of SSA in adults and, in particular, as a complication of prosthetic joints makes this case especially interesting. It is believed that the infection was triggered by her immunocompromised state, and that the gut was the most likely source of her $S$. enteritidis infection. The isolates recovered from the knee, blood and stool were identical in biotype, serotype, antibiotic sensitivity pro-

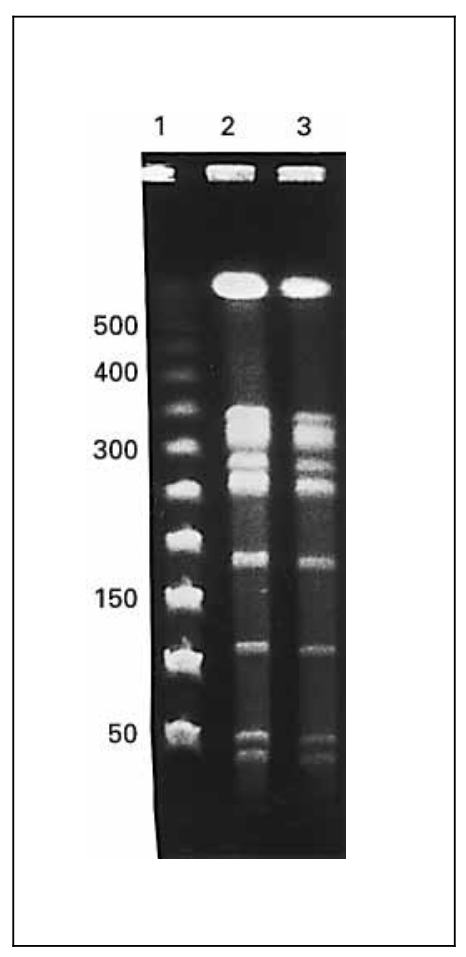

Fig. 1. PFGE of $X b a$ I digested chromosomal DNA of 2 strains of $S$. enteritidis. Lane 1 = size standards in $\mathrm{kb}$; lane $2=S$. enteritidis from blood culture; lane $3=$ S. enteritidis from knee aspirate.

files (the faecal isolate was not available at the time of testing) and the genetic make-up as demonstrated by the PFGE.

In an excellent review of the literature on SSA, Cohen et al. [7] cited the use of corticosteroid, systemic lupus erythromatosus, lymphoma and sickle cell disease as the main predisposing factors. Other reports have quoted HIV infection as another predisposing factor $[1,20]$. Our patient was diabetic, on steroid therapy, and the knee was compromised by the presence of a prothesis. The only other cases of SSA in prosthetic joints in the literature were those in patients with total hip replacement described by Samra et al. [21]. 
Table 1. Summary of the literature reports of Salmonella septic arthritis from 1982 to 1997

\begin{tabular}{|c|c|c|c|c|}
\hline References & Bacteria isolated (n) & Joint affected (n) & Predisposing conditions & Cases (n) \\
\hline Molyneux et al. [6] & $\begin{array}{l}\text { S. enteritidis }(5), \text { S. typhimurium (3), } \\
\text { S. paratyphi C (1), S. choleraesuis (1), } \\
\text { S. bovis-morbificans (1), NFI (9) }\end{array}$ & $\begin{array}{l}\text { shoulder (14), } \\
\text { knee (8) }\end{array}$ & malnutrition & 20 \\
\hline Brodie et al. [22] & S. dublin & multiple joints & none & 1 \\
\hline Petty et al. [20] & S. heidelberg & knee & none & 1 \\
\hline Quismorio et al. [15] & S. arizonae (3) & knee (3) & $\begin{array}{l}\operatorname{SLE}(1), \text { renal Tx (1), } \\
\text { macroglobulinaemia (1) }\end{array}$ & 3 \\
\hline Samra et al. [15] & S. typhi (3), S.muenchen (1) & hip (4) & total hip replacement & 4 \\
\hline Ebong [5] & Salmonella spp. ST not specified (10) & not specified & sickle cell disease & not specified \\
\hline Martin-Santos [23] & S. enteritidis & knee & heart transplant & 1 \\
\hline $\begin{array}{l}\text { Sankaran-Kutty } \\
\text { et al. [24] }\end{array}$ & Salmonella spp. ST not specified & hip (2) & sickle cell disease & 2 \\
\hline Medina et al. [25] & Salmonella group A (2), group B (7) & $\begin{array}{l}\text { knee (8), elbow (4), } \\
\text { ankle (2) }\end{array}$ & SLE & $\begin{array}{l}9, \text { multiple } \\
\text { jonts (4) }\end{array}$ \\
\hline Morgan et al. [4] & S. virchow & knee & none & 1 \\
\hline Govender et al. [2] & S. typhi & $\begin{array}{l}\text { Hip (4), knee (2), } \\
\text { sacro-iliac (3) }\end{array}$ & none & 9 \\
\hline Luo et al. [14] & S. typhimurium & not specified & HIV (2), none (1) & 3 \\
\hline Nduati et al. [12] & S. typhimurium (9), group D (1) & not specified & not specified & 10 \\
\hline Louthrenoo [1] & $\begin{array}{l}\text { S. choleraesuis (1), } \\
\text { S. enteritidis (1) }\end{array}$ & $\begin{array}{l}\text { sternoclavicular (1), } \\
\text { shoulder (1) }\end{array}$ & HIV & 2 \\
\hline Lavy et al. [3] & Salmonella spp. ST not specified & $\begin{array}{l}\text { shoulder (19), } \\
\text { knee (1) }\end{array}$ & $\begin{array}{l}\text { malnutrition } \\
\text { and anaemia }\end{array}$ & $\begin{array}{l}19 \text {, multiple } \\
\text { joints (1) }\end{array}$ \\
\hline
\end{tabular}

Another patient, a renal transplant recipient, a 36-year-old woman with systemic lupus erythromatosus who had a total hip replacement has been reported to develop SSA, not in her prosthetic hip joint, but in her right knee [7]. Similar to our patient, Salmonella was isolated from her knee aspirate, blood and faeces. A distinction should be made between the SSA described in our patient and post- infectious arthritis (reactive arthritis) arising from past infective diarrhoea. The latter is usually caused by an immune response, and people who develop such arthritis subsequent to salmonella gastroenteritis often have a specific histocompatibility antigen HLA-B27 [22]. The condition described in our patient is a septic process requiring drainage and antibiotic management as distinct from reactive 
arthritis that does not require this line of management.

Isolation of Salmonella for the diagnosis of SSA is necessary not only from the stool and blood culture, but also from the joint aspirate, since patients with reactive arthritis may also present with painful swelling of the joint. Nearly two-thirds of the cases will have positive blood culture, over $42 \%$ will have positive stool culture, and in more than $50 \%$, the gram stain of the joint aspirate is positive [7]. All these were positive in our patient. $S$. enteritidis belongs to the serological group $\mathrm{D}$, the group which also contains the typhoidal Salmonella, both of which have been implicated in SSA. S. enteritidis usually produces local symptoms in the gastrointestinal tract, but can occasionally become invasive, particularly in compromised hosts [4]. The immune status of our patient was compromised in two ways, by diabetes and the use of drugs such as methotrexate and corticosteroids. S. enteritidis and $S$. typhimurium are the commonest serotypes in Kuwait [23], a pattern similar to the prevalent serotypes in the Indian subcon- tinent. It is conceivable that our patient became colonized/infected by this strain in the gastrointestinal tract, probably from food, and through transient bacteraemia, the organism was deposited in the prosthetic joint thereby causing septic arthritis.

It was remarkable that the patient responded well to medical treatment and repeated aspiration on a few occasions. This good response contrasts with the poor outcome in patients with non-salmonella arthritis caused by other gram-negative bacteria and agrees essentially with an earlier experience reported by Morgan et al. [4]. The question as to which method of aspiration should be used to treat cases of SSA, needle or open drainage, is a matter of continued debate [2426]. However, our present experience, which concurs with Lavy et al. [3], shows that SSA can be successfully treated with aggressive intravenous antimicrobial chemotherapy for at least 2-3 weeks and for longer periods, e.g. 4 weeks, as in this case, when the patient is immunocompromised or has a prosthetic joint.

\section{References}

1 Louthrenoo W: Salmonella septic arthritis in patients with human immunodeficiency virus infection. J Rheumatol 1993;20:1454.

2 Govender S, Chotai PR: Salmonella osteitis and septic arthritis. J Bone Joint Surg 1990;72:504-506.

3 Lavy CBD, Lavy VR, Anderson I: Salmonella septic arthritis of the shoulder in Zambian children. J R Coll Surg Edinb 1996;41:197-199.

4 Morgan MG, Forbes KJ, Gillespie SG: Salmonella septic arthritis: A case report and review. J Infect 1990;21:195-203.

5 Ebong WW: Septic arthritis in patients with sickle cell disease. $\mathrm{Br} \mathrm{J}$ Rheumatol 1987;26:99-102.
6 Molyneux E, French G: Salmonella joint infection in Malawian children. J Infect 1982;4:131-138.

7 Cohen JI, Bartlett JA, Corey GR: Extraintestinal manifestation of salmonella infections. Medicine 1987; 66:349-388.

8 Udo EE, Grubb WB: Genetic analysis of methicillin-resistant Staphylococcus aureus from a Nigerian Hospital. J Med Microbiol 1993;38: 203-208.

9 Nelson JD: The bacterial etiology and antibiotic management of septic arthritis in infants and children. Pediatrics 1972;50:437-440.

10 Sequeira W: Septic arthritis in childhood. Ann Emerg Med 1985;14: 1185-1189.
11 Kempe CH, Silver HK, O'Brien D: Current paediatric diagnosis and treatment. Los Altos, Lange Medical Publications, 1984.

12 Nduati RW, Wamola IA: Bacteriology of acute septic arthritis. J Trop Pediatr 1991;37:172-175.

13 Ortiz-Neu C, Marr SJ, Cherubin EC, Neu HC: Bone and joint infection due to salmonella. J Infect Dis 1978;138:820-828.

14 Petty BG, Sowa DT, Charache P: Polymicrobial polyarticular septic arthritis. JAMA 1983;249:20692072.

15 Quismoria FP Jr, Jakes JT, Zarnow AJ, Barber D, Kitridou RC: Septic arthritis due to Arizona hinshawii. J Rheumatol 1983;10:147-150. 
16 Brodie TD, Ehresmann GR: Salmonella dublin arthritis: An initial case presentation. J Rheumatol 1983;10: 144-146.

17 Martin-Santos JM, Alonso-Pulpor L, Pradas G, Cuervas-Mons V, Anguita M, Mulero-Mendoza J, Escribano E, Martinez-Beltran J, Figuera-Aymerich D: Septic arthritis by Salmonella enteritidis after heart transplant. J Heart Transplant 1987; 6:177-179.

18 Sankaran-Kutty M, Sadat-Ali M, Kutty MK: Septic arthritis in sicklecell disease. Int Orthop 1988;12: 255-257.
19 Medina F, Fraga A, Lavalle C: Salmonella septic arthritis in systemic lupus erythematosus. The importance of the chronic carrier state. J Rheumatol 1989;16:203-208.

20 Luo NP, Perera CU, Zumla A: Salmonella septic arthritis. J Infect 1991;23:101

21 Samra Y, Shaked Y, Maier MK Non-typhoidal salmonellosis in patients with total hip replacement: Report of four cases and review of the literature. Rev Infect Dis 1986; 8:978-983

22 Hakansson U, Low B, Eitrem R, Winblad S: HLA-27 and reactive arthritis in an outbreak of salmonellosis. Tissue Antigen 1975;6:366367.
23 Jamal WY, Pal T, Rotimi VO, Chugh TD: Serogroups and antimicrobial susceptibility of clinical isolates of Salmonella species from a teaching hospital in Kuwait. J Diarrhoeal Dis Res 1998;16:180-186.

24 Schmidt D, Mubarak S, Gelberman $\mathrm{R}$ : Septic arthritis in children. J Paediatr Orthop 1981;1:67.

25 Dunkle LM: Towards optimum management of serious focal infections: The model of supurative arthritis. Paed Infect Dis J 1989;8: 195-196.

26 Petty RE: Septic arthritis and osteomyelitis in children. Curr Opin Rheumatol 1990;2:616-621. 